\title{
Developing Mechanistic Understanding of the Effect of Temperature and Environment on the Hold Time Fatigue Behavior of Haynes 282 Alloy
}

\author{
D. Ellis ${ }^{1}$, T. Hanlon ${ }^{1}$, C. Shen ${ }^{1}$, and E. Hall ${ }^{1}$ \\ ${ }^{1 .}$ GE Global Research, Niskayuna, NY, USA
}

Advanced ultra-supercritical coal-powered steam plants achieve significant efficiency gains via higher operating temperatures and pressures than existing plants. A significant challenge is developing materials for these more aggressive operating conditions and environment. This study was undertaken to develop an understanding of the hold time fatigue mechanism of the Ni-based superalloy Haynes 282 and to separate out the environmental and creep effects of the fatigue behavior. Crack growth rate experiments on samples of Haynes 282 were conducted at temperatures of 1200,1400, and 1600F in air, steam, and vacuum environments (compact tension sample, $25 \mathrm{ksi}$ in $1 / 2, \mathrm{R}=0.1$ ). Foils from tested samples were then prepared from the bulk free surface oxide and from the fracture surface adjacent to and far from the crack tip using focused ion beam scanning electron microscopy (FIB-SEM). Transmission electron microscopy (TEM) was used to identify various phases present in the resulting oxides, with an attempt to correlate structure to crack growth rate.

Figure 1 shows crack growth rate data from samples tested at 1200, 1400, and 1600F in air, steam, and vacuum conditions. At $1200^{\circ} \mathrm{F}$ and $1400^{\circ} \mathrm{F}$, crack growth rates are accelerated in steam, and delayed in vacuum, with respect to the air tests. However at $1600 \mathrm{~F}$, crack growth rates among the three environments tend to converge. The data suggest a pure environmental fatigue interaction at $1200 \mathrm{~F}$, a predominantly environmental-fatigue interaction at $1400 \mathrm{~F}$, and a pure creep-fatigue interaction at $1600 \mathrm{~F}$.

The oxide structure at the free surfaces of all the samples was similar showing internal $\mathrm{Al}_{2} \mathrm{O}_{3}$ oxidation, gamma prime phase depletion, and hexagonal $\mathrm{Cr}_{2} \mathrm{O}_{3}$ and Ti-rich oxides at the surface of the oxide. Figure 2 shows oxide structure at the crack tip for samples tested at $1400 \mathrm{~F}$ in air and steam. A key observation is the delayed formation of $\mathrm{Al}_{2} \mathrm{O}_{3}$ and $\mathrm{Cr}_{2} \mathrm{O}_{3}$ at the crack tip of specimens tested in air versus those tested in steam. Despite having a higher free energy of formation, mixed Ni oxides form first at the crack tip in air, leaving in their wake a large degree of local porosity. In contrast, specimens tested in steam, under a lower oxygen partial pressure, formed thick continuous layers of $\mathrm{Cr}_{2} \mathrm{O}_{3}$ directly at the crack tip, with limited porosity. The degree of porosity formed at the crack tip in air is believed to promote a more compliant crack tip, relative to the thick $\mathrm{Cr}_{2} \mathrm{O}_{3}$ layer, and is thought to retard crack propagation through crack path deflection and strain accommodation.

In summary, environmental-fatigue interactions dominated at temperatures of $1400 \mathrm{~F}$ and below. At 1600F, some environmental interaction was detected even as creep effects were becoming dominant. Near-field crack tip oxidation characteristics, and not bulk oxidation resistance, drive the variation in the hold time fatigue behavior over the range of temperatures and waveforms evaluated. The transition from crack tip porous $\mathrm{NiO}$ and $\mathrm{Ni}$-rich spinel to dense $\mathrm{Al}_{2} \mathrm{O}_{3} / \mathrm{Cr}_{2} \mathrm{O}_{3}$ may accelerate hold time fatigue in steam environments. 
References:

[1] Acknowledgment: This work was supported by the Department of Energy National Energy Technology Laboratory under Award No. DE-FE0005859.

[2] Disclaimer: This report was prepared as an account of work sponsored by an agency of the U.S. Government. Neither the U.S. Government nor any agency thereof, nor any of their employed, makes any warranty, express or implied, or assumes any legal liability or responsibility for the accuracy, completeness, or usefulness of any information, apparatus, product, or process disclosed, or represents that its use would not infringe privately owned rights. Reference herein to any specific commercial product, process, or service by trade name, trademark, manufacture, or otherwise does not necessarily constitute or imply its endorsement, recommendation, or favoring by the U.S. Government or any agency thereof. The views and opinions of authors expressed herein do not necessarily state or reflect those of the U.S. Government or any agency thereof.

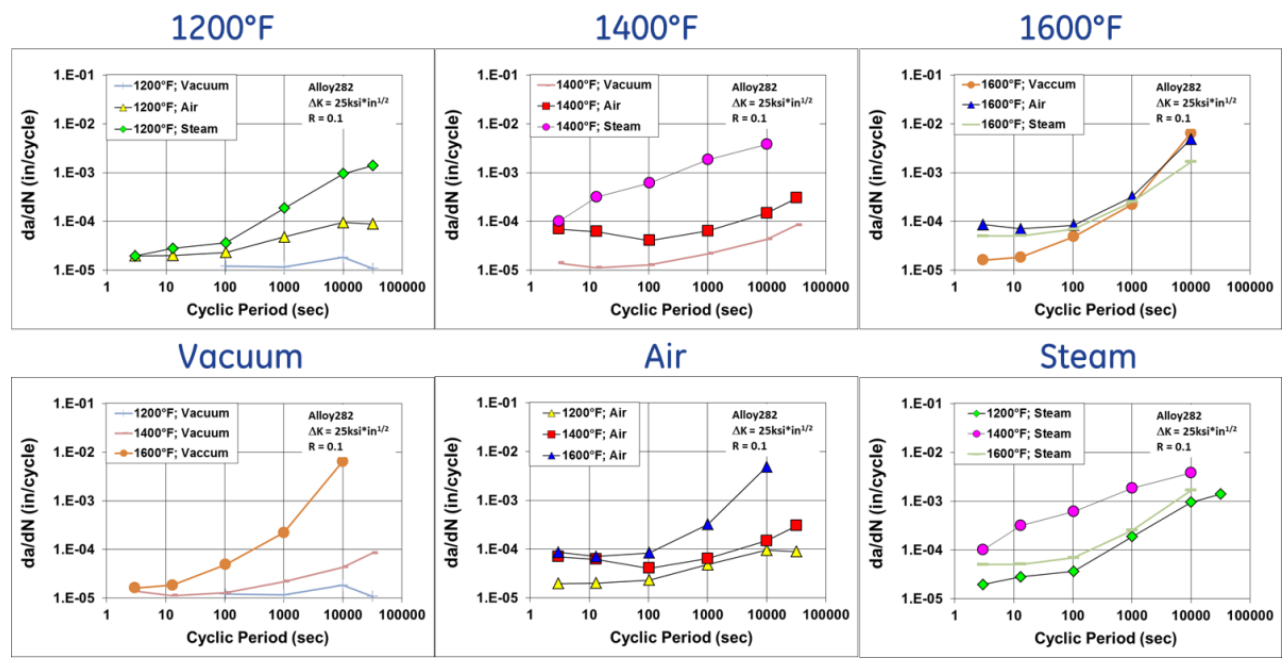

Figure 1. Crack growth rate for Haynes 282 at 1200, 1400, 1600F in air, steam, and vacuum.

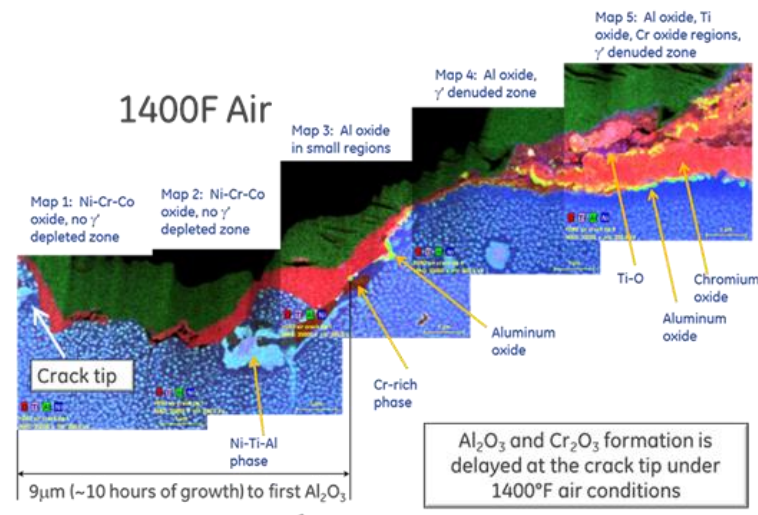

$1 \mathrm{um}$

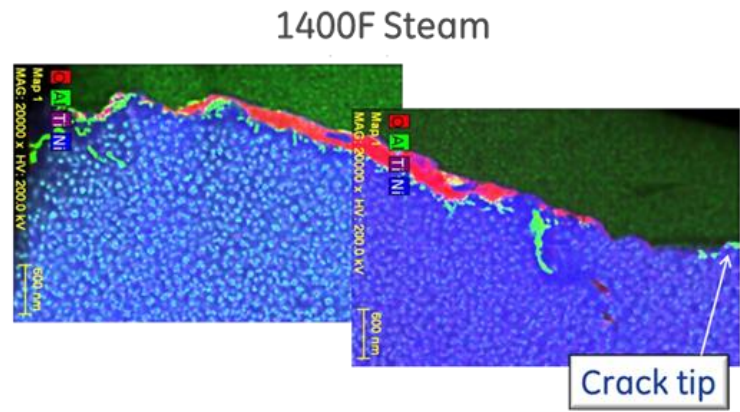

$600 \mathrm{~nm}$

Figure 2. $\mathrm{O}, \mathrm{Al}, \mathrm{Ti}, \mathrm{Ni}$ (red, green, purple, blue respectively) TEM EDS maps at crack tip of samples tested at $1400 \mathrm{~F}$ in air and steam. 